\title{
APPROACHES TO THE INDUCTION OF E-LEARNING STUDENTS: LAYING THE PEDAGOGIC FOUNDATIONS FOR SUCCESSFUL RELATIONAL E-LEARNING
}

\author{
H. Partington, J. Duckworth, D. Gurbutt \\ University of Central Lancashire (UNITED KINGDOM)
}

\begin{abstract}
E-learning students beginning their studies at a Higher Education Institution (HEI) have similar needs to campus-based students. Whether e-learning or campus-based, all students embarking upon a programme of study need opportunities for orientation, making connections and building confidence in themselves as learners. However, e-learners may be overlooked during induction with little at an institutional level to support their participation as a member of the learning community. Whilst HEls offer campus tours and various social events for campus-based students, e-learners may lack a 'tour guide' to show them around an unfamiliar virtual landscape which also encompasses university systems, learning technologies and a Virtual Learning Environment (VLE).

This paper draws on the authors' extensive experience delivering postgraduate e-learning courses and proposes that a relational approach to the induction of e-learners can build foundations for student success. The model for an e-learning induction process is the culmination of 13 years of reflective and evolving practice which places consideration of the e-learning student's perspective at the root of the model. The authors suggest that effective induction processes should orientate e-learners and familiarise them with the territory; they should facilitate e-learners' connections with their fellow students, tutors and the university/institution; and enable them to build foundations to support their emerging confidence as successful e-learners.
\end{abstract}

Keywords: E-learning, Online, Induction, Relational Pedagogy.

\section{INTRODUCTION}

Whether e-learning or campus-based, all students embarking upon a programme of study need opportunities for orientation, making connections and building confidence in themselves as learners. However, e-learners may be overlooked during induction with little available at an institutional level to support their participation as a member of the learning community. Whilst HEls offer campus tours and various social events for campus-based students, e-learners may lack a 'tour guide' to show them around an unfamiliar virtual landscape which also encompasses university systems, learning technologies and a Virtual Learning Environment (VLE).

This paper draws on the authors' extensive experience of delivering postgraduate e-learning courses and proposes that a relational approach to the induction of e-learners can build foundations for student success. The model for an e-learning induction process is the culmination of 13 years of reflective and evolving practice which places consideration of the e-learning student's perspective at the root of the model. The authors suggest that effective induction processes should orientate e-learners and familiarise them with the territory; they should facilitate e-learner's connections with their fellow students, tutors and the university/institution; and enable them to build foundations to support their emerging confidence as successful e-learners.

Two of the authors of this paper, Hazel and Jean, are senior lecturers who have been delivering master's programmes entirely by e-learning for over 13 years in the Faculty of Health and Wellbeing (FHW) at the University of Central Lancashire (UCLan) in Preston, UK. They have been supported in this endeavour by their critical friend, Dawne, who was originally their principal lecturer and is now Professor of collaborative learning and teaching at UCLan. During this time, they have continuously engaged in reflection both in and on action (Ref) regarding how to best support their e-learning students. This paper focuses in particular on the induction process for e-learning students and its importance in laying a strong foundation for an optimal learning experience. Induction is a crucial time in a student's university life and can make a big difference to how they experience the course and sometimes whether or not they continue on the course 
The courses currently being led by the authors are MSc Sustainability, Health and Wellbeing and MSc Transforming Integrated Health and Social Care. Both courses are open to a wide range of professions within health and social care fields. The e-learning delivery of these courses facilitates engagement from students all over the world. Additionally, the authors lead and teach on several e-learning modules which may be accessed by students from other campus-based courses to provide then with a blended learning experience. Our students are generally mature students, who often hold professional qualifications and have considerable professional experience although it may be some time since they completed academic study.

\section{METHODOLOGY}

This paper describes a present moment in the evolution of an induction process designed to give elearners a strong start to their studies and build strong foundations for future studies and successful relationships with tutors and fellow students. The evolution of the induction process and other aspects of the courses is ongoing from year to year and is open to change in the future according to students' needs and technological developments. In effect this forms an ongoing action research approach with continuous evaluation via staff reflection and student feedback any modifications to the courses or modules are highlighted in a 'you said, we did' section in course and module handbooks. In terms of the induction process outlined in this paper, the authors' engagement in reflective practice both in and on action [1] involved a consideration of the needs of new students and the similarities and differences between campus-based and e-learning students and the institutional provisions available. Feedback from past and current students further informed the process.

\section{RESULTS}

Three key needs for new students were identified:

1 Orientation

2 Opportunities for socialisation

3 Opportunities to build confidence in themselves as learners

These needs may be seen to apply equally to campus-based and distance learning students, however, the ways of meeting these needs are necessarily different due to the non-locality of e-learning students. Indeed, it may be said that e-learning students represent a significant 'absent presence' on $\mathrm{HEI}$ campuses. This body of invisible students may not be able to participate physically in freshers' week activities but still need to orientate themselves to an unfamiliar virtual landscape, form connections with their tutors and fellow students, and gain confidence in themselves as learners.

\subsection{Key needs during the induction period}

\subsubsection{Orientation}

The orientation process provided for new students on the e-learning courses under discussion has evolved over several years. When Hazel and Jean first began teaching on e-learning courses they found that there was very little guidance available as to how best to manage induction for e-learning students. They began by metaphorically putting themselves into the students' shoes and thought about what they would need to help orientate them to an unfamiliar virtual landscape. With this in mind the induction process was built to help orientate new e-learners to the various university and external systems used in the delivery of the courses systems by assigning them a series of small tasks under the guidance of a named member of the teaching team. The ethos of the course is to build, from the outset, a community of learners which hopefully will develop into a community of practice [2]. This ethos underpins all the activities, encouraging not just participation, but connection. Tasks include making skype contact with Jean and from there to meet in the Adobe Connect room that is used for synchronous tutorials. Tasks led by Hazel include posting on the asynchronous discussion boards. Clear step by step instructions are provided to introduce students to the VLE hosted on Blackboard, the university email system, and the wealth of electronic resources available from the library.

\subsubsection{Opportunities for socialisation}

The importance of socialisation for e-leaners is supported by Garrison [3] and Preece [4] who suggest that socialisation of e-learners can be a significant factor in both student retention and ultimately 
successful outcomes of their studies. Salmon's 5-step model [5] points to socialisation as an important aspect in becoming an e-learner and one requiring significant input from an e-tutor. The responsibility for facilitation of social introductions and developing socialisation between students lies much more with tutors in a VLE than in more traditional learning environments where students can introduce themselves and strike up conversations before and after lectures [6,7].

The authors have found a number of strategies useful to facilitate e-learners' formation of connections with staff, fellow students and the institution.

- Course leaders make sure that they have spoken to every new student before they start on the course, usually this is via skype, although if students live within travelling distance they are welcome to arrange a meeting on campus.

- Students are invited to contribute a short informal biography with a photo of themselves to the 'Getting to know each other folder' hosted on the VLE. Staff provide examples of their own biographies which aim to strike a balance between informing students about their academic background with more informal information such as hobbies or favourite places to holiday. The 'Getting to know each other' folder is available for the duration of the student's time on the programme, so if a student needs to change their cohort for any reason they can easily familiarise themselves with their new cohort.

- The use of asynchronous discussion boards both for academic discussions, and for informal discussions and sharing of relevant news and resources. Last year, the course team switched from using the discussion boards facility provided on the Blackboard VLE, to using Microsoft Teams which has more of a social media vibe with the facility for instant messaging and video calls built in. The more user-friendly features of Microsoft Teams appear to have increased students' engagement with the asynchronous discussion boards. Additionally, as Teams has the facility for students to set photos of themselves as avatars, interactions seem less anonymous than the previous discussion boards and provide an experience that is more akin to using a social media app such as Facebook or WhatsApp.

- The use of synchronous facilitated online discussion sessions/tutorials hosted in Adobe Connect chat rooms. Students and tutors meet using webcams and microphones and are able to have discussions where they can see and hear each other in real time. Skype and Microsoft Teams video are both used for individual tutorials according to student preference.

- The acceptance that for e-learning students, the teaching staff are the face of the university and all its various services. While students are provided with clear signposts to university services, it is most often the teaching staff that are the first port of call. However, in collaboration with a wider group including the Technical Enabled Learning and Teaching Team (TELT) the authors are on a self-imposed mission to improve communications and connections between the institution and e-learning students.

\subsubsection{Opportunities to build confidence in themselves as e-learners}

As discussed under Orientation, students are assigned a series of tasks to scaffold learning and build confidence in their own abilities as independent, autonomous learners. The level of technological competence varies considerably among the student group; hence provision is made to meet students in the Adobe Connect room prior to any taught sessions to allay students' nervousness about this new media. Once the students have worked their way through the induction tasks they are in a position to concentrate on their learning with minimal worries about their use of different systems.

\subsection{Relational pedagogy}

The teaching team take the stance of 'guides on the side' rather than experts at the front of the class with a relational pedagogy that is firmly rooted in a student-centred approach and incorporates elements of Communities of Practice theory [2]. Use of a flipped classroom methodology [8] whereby students work through assigned learning materials prior to facilitated synchronous discussion in Adobe Connect allows for deep learning which is further extended by a continuation of classroom discussions and sharing of resources via asynchronous discussion boards in between sessions. Lecturers work in pairs to team teach, this began as a practical measure to mitigate technological challenges that may arise with one lecture leading the session and the second supporting students with technological difficulties. However, over time and as the induction process has helped to iron out some of the students' technological challenges, additional benefits of team teaching have emerged and students have fed 
back in that they value having two tutors available who can model an engagement in critical dialogue and offer a range of experience and perspectives. Team teaching thus helps to develop a conversational inclusive culture as learners witness and participate in academic discussion.

\subsection{Challenges}

Whilst e-learning offers many advantages to tutors and students in terms of flexibility, accessibility and a lower carbon footprint than campus-based learning, there are of course challenges for both staff and students. As alluded to above, students may find it difficult to connect with the institution as a whole and struggle to navigate access to wider services. Hence teaching staff are seen as the main interface between students and the institution. Staff tend to need to teach online from their home offices to avoid the noise of a busy shared office interfering with their delivery of teaching and learning, this can be seen as both an advantage and a disadvantage for instance when institutional meetings may require travel between two offices in a working day. Inevitably the technology itself presents occasional challenges for example when broadband signals fail, although this in itself can contribute to the democratisation of learning in that students can see that their tutors also occasionally suffer from gremlins in the system. Student isolation is a commonly cited challenge inherent in online courses. The authors believe that adoption of a relational pedagogy has gone a long way towards mitigating this problem on the courses under discussion, but vigilance is needed to identify when students are struggling so as to be able to offer appropriate support.

\section{CONCLUSIONS}

This paper has presented an example of how a relational pedagogic approach to induction with a clear identification of e-learning students' needs for orientation, and opportunities for socialisation and to build confidence in themselves as e-learners may help to build strong foundations for a successful journey through a programme of study. The paper closes with feedback received from a student on one of the online modules taught by Hazel and Jean. This student had studied the rest of her MSc on campus and opted to take an e-learning module to complete her course. She was extremely nervous at the prospect of online learning but as will be seen completed the module with a great improvement in confidence. The quote is lengthy but is reproduced here in full as it offers a summary of the approach outlined from the perspective of a student.

"This module has transformed my opinions, doubts and reservations about online learning. Prior to commencing the module, I was definitely a technophobe!! I am now converted to this way of learning and on reflection I wish I could have completed my MSc in this way from the start. The benefits to me were many. I will list a few below.

I felt like my learning experience was more personal. My relationship and contact with my tutors was more personal. In a classroom setting you can get lost amongst the other students. This method of learning allowed visual face to face contact during online sessions and I always felt like the tutors were easily accessible should I need to contact them with the help of the Teams app and therefore felt secure and well supported.

I also got to know and see my fellow colleagues more using this method of learning. In a classroom you may only get to know a few students. The opportunity to network and communicate between sessions was also encouraged using technology which fitted in more with my busy life as I could text/message/communicate at a time which suited me.

Being able to study in the comfort of my home was preferable too as it reduced wasted travel time (30mile round trip) and I felt more relaxed prior to starting the session rather than feeling stressed after getting through the traffic and getting parked to get to the university.

This method of delivering education also saved me money on fuel costs and childcare costs (one of my sessions was in the school holidays so my 7-year-old could just play in her room whilst I was online)"

\section{ACKNOWLEDGEMENTS}

The authors are grateful to the University of Central Lancashire for their financial support to submit this paper. 


\section{REFERENCES}

[1] D. A. Schon \& V. DeSanctis, "The Reflective Practitioner: How Professionals Think in Action", The Journal of Continuing Higher Education, vol. 34, no.3, pp. 29-30, 1986.

[2] J. Lave, \& E. Wenger, Situated learning: legitimate peripheral participation. Cambridge: Cambridge University Press, 1999.

[3] D.R. Garrison, E-learning in the $21^{\text {st }}$ Century: A framework for research and practice. Abingdon: Routledge Falmer, 2011.

[4] J. Preece, Online communities: Designing usability, supporting sociability. New York: Wiley, 2000.

[5] G. Salmon, E-moderating: The key to teaching and learning online (2nd edition.) Abingdon: Routledge Falmer, 2003.

[6] E. Hootstein, Wearing Four Pairs of Shoes: The roles of e-learning facilitators. Association for Talent Development, 2002 Retrieved from: https://www.td.org/Publications/Newsletters/Learning-Circuits/Learning-CircuitsArchives/2002/Wearing-Four-Pairs-of-Shoes.

[7] R. M. Conrad, J.A. \& Donaldson, Engaging the Online Learner: Activities and Resources for Creative Instruction. San Francisco: Jossey-Bass, 2005.

[8] Tucker, B. (2012) The flipped classroom. Education Next, 12(1) Available from: https://search. proquest.com/docview/1237826701?accountid=17233 Accessed 22.5.17 